\title{
Using a profile of a modified Brief ICF Core Set for chronic widespread musculoskeletal pain with qualifiers for baseline assessment in interdisciplinary pain rehabilitation
}

\author{
This article was published in the following Dove Press journal: \\ Journal of Multidisciplinary Healthcare \\ 27 August 2013 \\ Number of times this article has been viewed
}

\author{
Monika Löfgren ${ }^{1,2}$ \\ Jan Ekholm² \\ Lisbet Broman ${ }^{3}$ \\ Philipe Njoo' \\ Marie-Louise Schult ${ }^{1-3}$ \\ 'Department of Rehabilitation \\ Medicine Stockholm, Danderyd \\ University Hospital, Sweden; \\ ${ }^{2}$ Karolinska Institutet, Division of \\ Rehabilitation Medicine, Department \\ of Clinical Sciences, Danderyd \\ University Hospital, Stockholm, \\ Sweden; ${ }^{3}$ Karolinska Institutet, \\ Department of Neurobiology, Care \\ Sciences and Society, Stockholm, \\ Sweden
}

Aim: To describe the use of a "workable" visual profile of function and disability, based on a modified Brief International Classification of Functioning, Disability and Health (ICF) Core Set for chronic widespread pain, for initial assessments in a clinical setting of interdisciplinary pain rehabilitation teams.

Method: The Brief ICF Core Set was slightly adapted to meet the needs of an interdisciplinary rehabilitation medicine team working in a university outpatient clinic and admitting patients referred from primary care. The Core Set categories were made measurable by means of eg, assessment instruments and clinical investigations. The resulting profile was given a workable shape to facilitate rapid understanding of the initial assessment outcome.

Results: Individual patients showed different profiles of problems and resources, which facilitated individual rehabilitation planning. At the level of the study group, the profiles for the Core Set component Body Functions showed that most patients had severe impairment in the sensation of pain and exercise tolerance categories of function, but most had resources in the motivation and memory categories of function. Likewise, for the component Activities, most patients had limitations in lifting and carrying objects and remunerative employment, but most had resources in intimate relationships and family relationships. At first, the use of the modified Brief ICF Core Set in the team conference was rather time consuming, but after a couple of months of experience, the team assessment took approximately 30 minutes to complete per patient.

Conclusion: The profile of the modified Brief ICF Core Set for chronic widespread pain served as a common platform, facilitating cooperation between the rehabilitation team members and providing a uniform language, which helped in structuring the clinical work. The profile also provided an easily accessible, overall view of the patient's problems and resources, which helped in understanding the functioning situation of the patient.

Keywords: ICF, interdisciplinary teamwork, chronic widespread pain, assessment

\section{Introduction}

In many countries, specialized health care and rehabilitation for patients with longterm/chronic pain conditions is provided by pain rehabilitation clinics or "pain clinics." Rehabilitation for patients with long-term pain is often performed by interprofessional teams. ${ }^{1-3}$ This teamwork involves the patient and all team members working together in goal setting, planning of interventions, and evaluation of the rehabilitation (ie, evaluation of the interdisciplinary teamwork). ${ }^{4-6}$ An important task for these clinics is to evaluate patient functioning and disabilities. The literature indicates that the International Classification of Functioning, Disability and Health (ICF) ${ }^{7}$ could be a helpful resource to
Correspondence: Monika Löfgren Department of Rehabilitation Medicine Stockholm, Bldng 39, Floor 3, Danderyd University Hospital, 18288 Stockholm, Sweden $\mathrm{Tel}+468 \mathrm{I} 2357813$

Email monika.lofgren@ki.se 
provide a holistic, yet condensed picture of patient functioning and disabilities for this kind of evaluation. In a regular clinical setting, with its demand for high tempo, it is advantageous for the evaluation to be given a practical and "workable" shape. In this study, just such an easy-to-read version of the ICF categories was tested as a basis for evaluation.

The ICF provides a large number of categories covering different domains and therefore seems useful in the context of an interdisciplinary rehabilitation team, where different professions address different aspects of the ICF. The use of the ICF model seems helpful in directing our attention to different aspects of functioning rather than on focusing on diagnostic procedures. ${ }^{8}$ To facilitate its clinical application, comprehensive Brief ICF Core Sets have been developed for different diagnoses, such as low-back pain (LBP) ${ }^{9}$ and chronic widespread pain (CWP). ${ }^{10}$

One study examined whether it was feasible to construct a psychometrically sound clinical instrument to measure functioning in fibromyalgia, based on the Brief ICF Core Set for CWP. ${ }^{11}$ The study illustrated that it is possible to measure functioning as a unidimensional construct based on selected ICF categories. Following the analysis process, 14 of the 24 ICF categories remained in the model, each showing good fit to the model.

A systematic literature review spanning 2001 to 2009 included 32 papers describing practical clinical applications of the ICF and 47 papers describing its use for specific conditions. ${ }^{12}$ Of these papers, only two addressed the clinical context of long-term pain. ${ }^{8,13}$ The validity of the ICF Core Set for CWP was studied from the perspective of fibromyalgia patients, using focus groups. ${ }^{14}$ Patients reported 54 out of the 67 ICF categories in the earlier published version, and 48 additional categories not covered in the earlier presented version were identified. For instance, 27 and 15 additional concepts, respectively were linked to fine-motor hand use (d440) and hand and arm use (d445). Thirty-two additional concepts were linked to memory functions (b144).

No CWP study was found that focused on practical clinical applications, and therefore, LBP studies were used to introduce the topic, since LBP is another common long-term pain condition within rehabilitation. In one study, patients' with LBP were asked to specify their greatest difficulty arising from to their back pain and something they used to enjoy but were now unable to do because of their LBP. ${ }^{13}$ This was compared to the LBP Core Sets, and the authors recommended an addition of the categories Recreation and Leisure, and Caring for Household Objects to the LBP Brief ICF Core Set. Low to moderate reliability was found when using the LBP
Core Set, consequently the authors recommended improved operationalization of the categories. ${ }^{15}$

The Comprehensive ICF Core Set for LBP was tested for clinical use in patients with LBP, in a nationwide study in Norway. ${ }^{16}$ The authors concluded that it is possible to use the ICF in clinical settings. By using the ICF, the study personnel increased their knowledge about patients' body function, activity, participation, and influential environmental factors. It was important that the personnel were first adequately trained to perform the scoring of the qualifiers. During the study, seminars and emails were used to discuss difficulties and uncertainties, and this was found to be important to accomplishing a common interpretation of the categories and scoring.

In a validation study ${ }^{17}$ that aimed to identify candidate categories from the ICF to be included in the Brief ICF Core Set for LBP, twelve ICF categories were found to be significant explanatory factors, four of which were not included in the previously proposed Brief Core Set for LBP. ${ }^{9}$ This is one example of the ongoing scientific work to improve the practical clinical application of the ICF.

In another article, ${ }^{18}$ more studies were recommended to improve reliability and to identify the best methods for using the ICF in daily clinical practice. The authors argued that further clinical research is needed to improve the possibilities for clinical applications of ICF.

Research is relatively sparse on the benefits of using ICF as a basis for interdisciplinary team assessments of patients with long-term pain conditions. It seems that there is a lack of internationally published studies that use the Brief ICF Core Set (fully or in a modified version) for CWP in a clinical setting, for interdisciplinary assessments using qualifiers and visual profiles.

\section{Aim}

The aim here, was to describe a modified Brief ICF Core Set with qualifiers for CWP as a basis for the initial assessment of patients with long-term pain conditions in a clinical setting and for its use by an interdisciplinary pain rehabilitation team. To achieve this, a workable visual profile of the modified Brief ICF Core Set for CWP was applied to a sample of patients with long-term pain who were referred for interdisciplinary assessment and rehabilitation.

\section{Methods and material The modified Brief ICF Core Set for chronic widespread pain}

The rehabilitation team's need of a core set for assessment had the following criteria: (1) the profile's capacity should 
fit patients with long-term pain due to varied conditions of origin (but developed into widespread pain); (2) the category should match the needs of the clinical setting (not too time consuming to use, giving an overall view of the patient's problems); (3) the Core Set should facilitate clinical activity; (4) the comprehensive generic assessments included in the Swedish Quality Registry for Pain Rehabilitation (NRS) ${ }^{19,20}$ should fit the Core Set categories; (5) the amount of available information from the team members' assessments, including the NRS, should be enough to score the categories in the Core Set after the patients had seen each team member once; and (6) it should be possible to use different assessment methods for scoring the qualifiers, for eg, interviews, questionnaires, and physical examinations, as well as performance tests carried out to improve agreement in scoring.

The Brief ICF Core Set for CWP was selected based on the criteria above. ${ }^{10}$ It included 24 different categories. A slight modification of the Brief ICF Core Set was made; the list was intended to be as short as possible and only contain categories that could be scored during the limited time available at the first visit with each team member. Thus, psychomotor functions (b147), control of voluntary movement function (b760), content of thought (b1602), solving problems (d175), and support from health professionals (e355) were all excluded. Drugs (e1101) were managed by the Physical and Rehabilitation Medicine physician without the need for consensus discussions by the rehabilitation team.

Since energy level (b1300) and motivation (b1301) are different dimensions, the category of mental function (b130) was divided into two. Motivation is particularly important for rehabilitation potential and needs to be assessed separately. ${ }^{21}$ Since one of the important aims of the rehabilitation program was work resumption, the category fine hand use (d440) was also included. The profile adapted to the present project contained 21 categories, 18 of which were in agreement with the original Brief ICF Core Set for CWP. ${ }^{10}$

In the ICF, the amount of impairment/degree of difficulty/ degree of barrier is specified using five qualifiers scored from 0 to 4. These translate to "none," "mild," "moderate," "severe," and "complete." Each category was distributed to professionals within the team, according to the competence profile of the professional (Table 1). Thus, the category emotional functions (b152) was assessed by the psychologist, the social worker and the physician, while exercise tolerance function (b455) was assessed primarily by the physiotherapist, and doing housework (d640) was assessed by the occupational therapist.

Seminars on the use of the ICF classification, the scoring system, the linking of assessment methods to the categories, and the discussion of difficulties when quantifying the categories were arranged for the team.

The modified Brief ICF Core Set for CWP was used as the basis for the assessment; all patients underwent an interdisciplinary assessment during a 2 -week period.

\section{Interdisciplinary assessment}

The team consisted of a PRM physician, a nurse, a psychologist, a social worker, a physiotherapist, and an occupational therapist, all with many years of experience with pain rehabilitation. The assessment took the form of a clinical examination by the physician and physiotherapist, and each team member conducted a profession-specific interview and other investigations, lasting up to about 90 minutes. All patients also underwent comprehensive general assessments included in the NRS before the interdisciplinary assessment: the Short Form (SF)-36 ${ }^{\circledR}$ Health Survey (QualityMetric Inc, Lincoln, RI, USA), ${ }^{22}$ the Hospital Anxiety and Depression Scale (HAD), ${ }^{23,24}$ the EQ-5D, ${ }^{25}$ the Multidimensional Pain Inventory (MPI), ${ }^{26}$ and the Chronic Pain Acceptance Questionnaire. ${ }^{27}$ Other standardized tests and instruments employed were: the Test Instrument for the Profile of Physical Ability (TIPPA), ${ }^{28}$ the Assessment of Motor and Processing Skills, ${ }^{29}$ the Valpar Component Work Samples (VCWS), ${ }^{30}$ and the Tampa Scale for Kinesiophobia. ${ }^{31}$

At the end of the 2-week comprehensive assessment period, the pain rehabilitation team met for a team conference. The outcomes of all assessments, interviews, and tests were interpreted, discussed, and translated into a qualifier number by consensus. If consensus was not directly reached, the qualifier number supported by the responsible PRM physician was chosen.

The needs and goals of the patients' rehabilitation program were formulated based on discussions between the team members and the patients. Here, the Brief ICF Core Set profile was used as an essential guide during this planning process.

\section{Patients}

A consecutive series of 53 patients referred for interdisciplinary pain rehabilitation at an outpatient pain rehabilitation clinic at the Department of Rehabilitation Medicine at the Danderyd University Hospital, Stockholm, during September 2009 to May 2010 were all (18 men and 35 women) included for study (Table 2). Of these, $90 \%$ were referred from primary health care units and 10\% from other sources.

The exclusion criteria for pain rehabilitation were: current substance abuse, other current severe somatic or 
Table I ICF categories, ICF codes, assessment methods and rehabilitation team members involved in assessment

\begin{tabular}{|c|c|c|c|}
\hline $\begin{array}{l}\text { Modified Brief ICF Core Set } \\
\text { for chronic widespread pain }\end{array}$ & Code & $\begin{array}{l}\text { Operationalization/assessment } \\
\text { methods }\end{array}$ & Professions \\
\hline \multicolumn{4}{|l|}{ Body Functions } \\
\hline Energy and drive functions & b| 300 & $\begin{array}{l}\text { Interview } \\
\mathrm{SF}^{\circledR}-36 \text { : vitality }\end{array}$ & $1,2,3$ \\
\hline Motivation & bl30I & Interview & $1,2,3$ \\
\hline Sleep functions & bl34 & Interview & 1,6 \\
\hline Memory functions & bl44 & AQT & $1,2,4$ \\
\hline \multirow[t]{4}{*}{ Emotional functions } & bl52 & HAD & $1,2,3$ \\
\hline & & SF-36: mental functions & \\
\hline & & EQ-5D: anxiety and depression & \\
\hline & & Interview & \\
\hline \multirow[t]{6}{*}{ Sensation of pain } & b280 & VAS & $1,5,6$ \\
\hline & & SF: bodily pain & \\
\hline & & EQ-5D: pain and discomfort & \\
\hline & & Pain drawing & \\
\hline & & Clinical assessment & \\
\hline & & Interview & \\
\hline \multirow[t]{2}{*}{ Exercise tolerance functions } & b455 & TIPPA & 4,5 \\
\hline & & Valpar Component Work Sample & \\
\hline Muscle power functions & b730 & Clinical tests & $\mathrm{I}, 5$ \\
\hline \multicolumn{4}{|l|}{ Activity and Participation } \\
\hline \multirow[t]{6}{*}{ Carrying out daily routines } & $d 230$ & Interview & 4 \\
\hline & & SF-36: role-physical & \\
\hline & & SF-36: role-emotional & \\
\hline & & COPM & \\
\hline & & EQ-5D: usual activities and self care & \\
\hline & & MPI: activity index & \\
\hline Handling stress and other psychological demands & d240 & Interview & $1,2,3$ \\
\hline \multirow[t]{3}{*}{ Lifting and carrying objects } & $\mathrm{d} 430$ & TIPPA & 4,5 \\
\hline & & Valpar Component Work Samples & \\
\hline & & SF-36: physical function & \\
\hline Fine hand use & $\mathrm{d} 440$ & Valpar Component Work Samples & 4 \\
\hline \multirow[t]{2}{*}{ Walking } & $\mathrm{d} 450$ & SF-36: physical functioning & 5 \\
\hline & & TIPPA & \\
\hline Doing housework & $d 640$ & & 4 \\
\hline Family relationships & d760 & & $1,2,3$ \\
\hline Intimate relationships & d770 & & $1,2,3$ \\
\hline Remunerative employment & d850 & & $1,3,4$ \\
\hline Recreation and leisure & d920 & & $3,4,5$ \\
\hline \multicolumn{4}{|l|}{ Environmental Factors } \\
\hline Support from immediate family & e310 & & 2,3 \\
\hline Individual attitudes from immediate family & e410 & & 2,3 \\
\hline Social security service and policies & e570 & & $\mathrm{I}, 3$ \\
\hline
\end{tabular}

Notes: I = physician, 2 = psychologist, 3 = social worker, 4 = occupational therapist, 5 = physiotherapist, and $6=$ nurse.

Abbreviations: AQT, A Quick Test; COPM, Canadian Occupational Performance Measure; HAD, Hospital Anxiety and Depression scale; ICF, International Classification of Functioning, Disability and Health; MPI, Multidimensional Pain Inventory; SF ${ }^{\circledR}$-36, Short Form-36 Health Survey; TIPPA, Test Instrument for Profile of Physical Ability; VAS, visual analog scale.

psychiatric disease, inability to attend group interventions due to language or social barriers, or if previous adequate rehabilitation had not shown sustained results. The patients were all transferred to the same rehabilitation team (one team out of the seven teams at the pain rehabilitation clinic).

Different professions/work categories were represented by the patients: health care $(n=6)$, transportation $(n=4)$, cleaning $(n=2)$, restaurant/café $(n=5)$, teaching $(n=4)$, economics and self-employment $(n=6)$, and miscellaneous $(n=10)$. Sixteen were unemployed at the time of the assessment (Table 2). The patients had persistent pain for a mean of 7 years and an average pain intensity of 6.8 (on a numeric rating scale $0-10$ ). The mean number of pain locations was 16, and 44\% described their pain location as varying. Zigmond and Snaith ${ }^{24}$ suggested two cut off scores $\geq 11$ points for detecting depression and anxiety, 
Table 2 Sociodemographic data and self-assessment outcomes

\begin{tabular}{|c|c|c|c|c|}
\hline \multirow[t]{2}{*}{ Variables } & \multirow[t]{2}{*}{$\mathbf{N}$} & \multirow[t]{2}{*}{ Median } & \multicolumn{2}{|c|}{ Percentiles } \\
\hline & & & 25 & 75 \\
\hline \multicolumn{5}{|l|}{ Personal factors } \\
\hline \multicolumn{5}{|l|}{ Native country } \\
\hline Sweden & 25 & & & \\
\hline Other Nordic country & 2 & & & \\
\hline Other European country & 2 & & & \\
\hline Other country & 24 & & & \\
\hline \multicolumn{5}{|l|}{ Education level } \\
\hline Nine-year compulsory school & 12 & & & \\
\hline Upper secondary school & 23 & & & \\
\hline University & 15 & & & \\
\hline Other & 3 & & & \\
\hline \multicolumn{5}{|l|}{ Work situation } \\
\hline Employed & 37 & & & \\
\hline Unemployed & 16 & & & \\
\hline Age (years) & 53 & 47 & 39 & 52 \\
\hline \multicolumn{5}{|l|}{ HAD } \\
\hline \multicolumn{5}{|l|}{ Anxiety } \\
\hline $0-10$ points & 24 & & & \\
\hline||$-2 \mid$ points & 23 & & & \\
\hline \multicolumn{5}{|l|}{ Depression } \\
\hline $0-10$ points & 21 & & & \\
\hline||$-2 \mid$ points & 25 & & & \\
\hline TSK & 44 & 43.5 & 31.3 & 50.8 \\
\hline \multicolumn{5}{|l|}{ EQ-5D } \\
\hline Index & 46 & 0.04 & 0.00 & 0.19 \\
\hline VAS & 46 & 30 & 24 & 40 \\
\hline \multicolumn{5}{|l|}{ Health-related quality of life (SF-36) } \\
\hline Physical functioning & 47 & 50 & 30 & 60 \\
\hline Role - physical & 46 & 0 & 0 & 0 \\
\hline Bodily pain & 47 & 22 & 12 & 22 \\
\hline General health & 46 & 35 & 20 & 45 \\
\hline Vitality & 47 & 15 & 10 & 35 \\
\hline Social functioning & 47 & 38 & 25 & 50 \\
\hline Role - emotional & 45 & 0 & 0 & 33 \\
\hline Mental health & 47 & 44 & 32 & 66 \\
\hline PCS & 43 & 29 & 24 & 33 \\
\hline MCS & 43 & 30 & 23 & 40 \\
\hline
\end{tabular}

Abbreviations: HAD, Hospital Anxiety and Depression scale; $\mathrm{SF}^{\circledR}$-36, Short Form-36 Health Survey; MCS, Mental Component Summary; PCS, Physical Component Summary; TSK, Tampa scale for kinesiophobia; VAS, visual analog scale.

and accordingly, $51 \%$ in the present sample were depressed and $54 \%$ experienced anxiety, as measured by the HAD. The EQ-5D showed very low health-related quality of life and low self-perceived health. ${ }^{25}$ The SF-36 Health Survey subscales showed that all the patient's health was decreased and well below the Swedish norms (see Table 2) for the general population. ${ }^{22}$

\section{International Classification of Disease (ICD) diagnoses of the patients with chronic widespread pain}

During the patients' stay at the outpatient rehabilitation unit, a diagnostic investigation was performed in parallel with the functional assessment. The main, or major, diagnoses, as well as comorbidities, were established. In the current national insurance system, the major diagnosis (eg, for sickness allowances) is registered first in the documentation, followed by the comorbidity diagnoses (and in some documents, only the main diagnosis is available). The same principle with major diagnoses was applied for the registration in the National Pain Registry in the present study. This means that widespread pain need not be the main diagnosis; it may be an important comorbidity but consequently, not registered first in the document. For example, a spinal pain condition that has developed into a long-lasting widespread pain condition has the spinal diagnosis as the major and first registered diagnosis and widespread pain as a comorbidity. ${ }^{32}$ Further, a patient can have depression as the major diagnosis and widespread pain as a comorbidity. In the present study, the major diagnoses were used, and some of those are "widespread" by definition, such as fibromyalgia, osteoporosis, and generalized pain (Table 3, upper 26 patients). However, others are regional or local diagnoses, and therefore, the number of pain locations was used as an indicator of the spreading of pain, in addition to the regional/local diagnosis (Table 3, lower 27 patients).

\section{Data analysis and statistics}

The IBM SPSS statistics software (version 18.0; IBM, Armonk, NY, USA) was used for the analyses.

Descriptive statistics was used for describing the patients' level of functioning and disability for each category (Table 2); the ICF qualifiers ranging from 0 to 4 were used, ${ }^{7}$ and the percentages of ratings within the above qualifier groups, respectively, were calculated.

\section{Results}

\section{Individual profiles}

The available individual profile, obtained from the scoring of the modified Brief ICF Core Set for CWP, can be used as a basis for individual rehabilitation plans and goal setting, thus serving as a link between assessment and interventions. An individual profile also gives an easily accessible rapid overall view of the patient's problems and resources, which helps understanding of the functional level of a patient.

Two examples, Cases 1 and 2, of visualized profiles illustrate different patterns of functioning and disability (Figure 1).

\section{Case I}

Case 1 was a male patient of 37 years, diagnosed with generalized pain. He was born in a country outside Europe. 
Table 3 Main diagnoses, according to ICD-10, of the patients with widespread pain conditions and the number of pain locations as an indicator of the spreading of pain

\begin{tabular}{|c|c|c|c|c|}
\hline $\begin{array}{l}\text { Primary diagnosis/ICD-10 diagnosis } \\
\text { group }\end{array}$ & ICD chapter + code & $\begin{array}{l}\text { Number } \\
\text { of patients }\end{array}$ & $\begin{array}{l}\text { Number of pain } \\
\text { locations, mean }\end{array}$ & $\begin{array}{l}\text { Number of pain } \\
\text { locations, median }\end{array}$ \\
\hline Generalized pain & R52.9 & 14 & $13.5^{*}$ & $12^{*}$ \\
\hline Fibromyalgia & M79.0 & 6 & 28.2 & 32 \\
\hline Arthropathy & MI2.8 & 1 & 27 & \\
\hline Osteoporosis & M8I.0 & 1 & 15 & \\
\hline Chronic pain or ache & R52.2 & $4 * *$ & $17^{* * * *}$ & $16 * * *$ \\
\hline Subtotal & & 26 & & \\
\hline $\begin{array}{l}\text { Section spinal diseases, M-chapter } \\
\text { musculoskeletal and connective tissue diseases }\end{array}$ & $\begin{array}{l}\text { M43.6, M47.2, M5I.0, M53.I, } \\
\text { M54.2, M54.5, M54.8 }\end{array}$ & 13 & $12.6^{\#}$ & $12.5^{\#}$ \\
\hline $\begin{array}{l}\text { Section diseases in shoulder, M-chapter } \\
\text { musculoskeletal and connective tissue diseases }\end{array}$ & M75.I, M75.4 & 2 & 15 & \\
\hline Primary gonarthrosis & MI7.I & 2 & 14 & \\
\hline $\begin{array}{l}\text { M-chapter: other musculoskeletal and } \\
\text { connective tissue diseases }\end{array}$ & M96.0, M99.0 & 2 & 4 & \\
\hline Diseases in nerve roots and plexuses & G54.0 & I & 14 & \\
\hline Depression, anxiety & F32.2, F4I.I, F4I.2, F4I.9 & 6 & 19.5 & 17.5 \\
\hline Pain from abdomen and pelvis & $\mathrm{RI} 0.3$ & 1 & 7 & \\
\hline Subtotal & & 27 & & \\
\hline Total & & 53 & & \\
\hline
\end{tabular}

Notes: $\mathrm{N}=53$. *Due to some uncertainty as regards the documentation, two patients were not included in the calculation, $\mathrm{n}=12$; $* *$ for one patient, the documentation was unclear; ***calculated on $\mathrm{n}=3$; \#due to some uncertainty as regards the documentation, three patients were not included in the calculation, $\mathrm{n}=10$.

Abbreviations: ICD, International Classification of Disease; M-chapter, diseases of the musculo-skeletal system and connective tissue.

His highest education level was upper secondary school, and he worked as a taxi driver but had not been working for 37 months, on the grounds of sick leave. He scored a high degree of depression (HAD score 20) and anxiety (HAD score 16) and rated a low quality of life, ie, EQ-5D index $=0$ $[-1$ to 1$]$ and EQ-5D visual analog scale (VAS) $=15$ [0 to 100]. The individual profile illustrates severe and even total impairment of the Body Functions presented (Figure 1). The components of Activity and Participation illustrate severe limitations in seven categories but mild limitations in only two. Severe barrier was assessed in one category and mild/ no barriers in two. Resources were seen in two categories within the component Activity and Participation, with only mild limitations and no problems regarding social security services, systems, and policies.

\section{Case 2}

Case 2 was a male patient of 45 years, diagnosed with cervicobrachial syndrome and CWP. He was born in a country outside Europe. His highest education level was university degree. He was working as an employment officer and was not, at the time of study, on sick leave. He showed no signs of depression according to the HAD (HAD score 5 ) but some degree of anxiety (HAD score $=11)$. He had low quality of life, ie, EQ-5D index $=0.19$ and medium EQ-5D VAS $=60$. The individual profile of case 2 (Figure 1 ) illustrates mild or no impairments in seven and moderate impairment in only one of the Body Functions presented. The dimension of Activity and Participation illustrated no or mild limitations in seven categories and moderate or severe limitations in only one. Moderate barriers were assessed in the two categories presented. Resources were seen in all Body Functions but pain, and in all but three activities (handling stress, family relationships and intimate relationships).

The profiles of the two individuals show different patterns of problems and individual resources. The differences in profiles influenced the rehabilitation planning.

Note that, as seen in Figure 1, all steps in the ICF qualifier scale were utilized.

\section{The use of group profiles}

Almost all of the categories' qualifiers were scored by one to three team members/professions using different assessment methods (Table 1). As described in Methods, consensus about the scoring number was reached at a team conference.

In the group profiles, the 53 patients showed major limitations/restrictions in the ICF component Activity and Participation. In all categories, the qualifiers none, mild, moderate, and severe were used. The qualifier "complete" was only applicable in a few categories. Thus the scale 

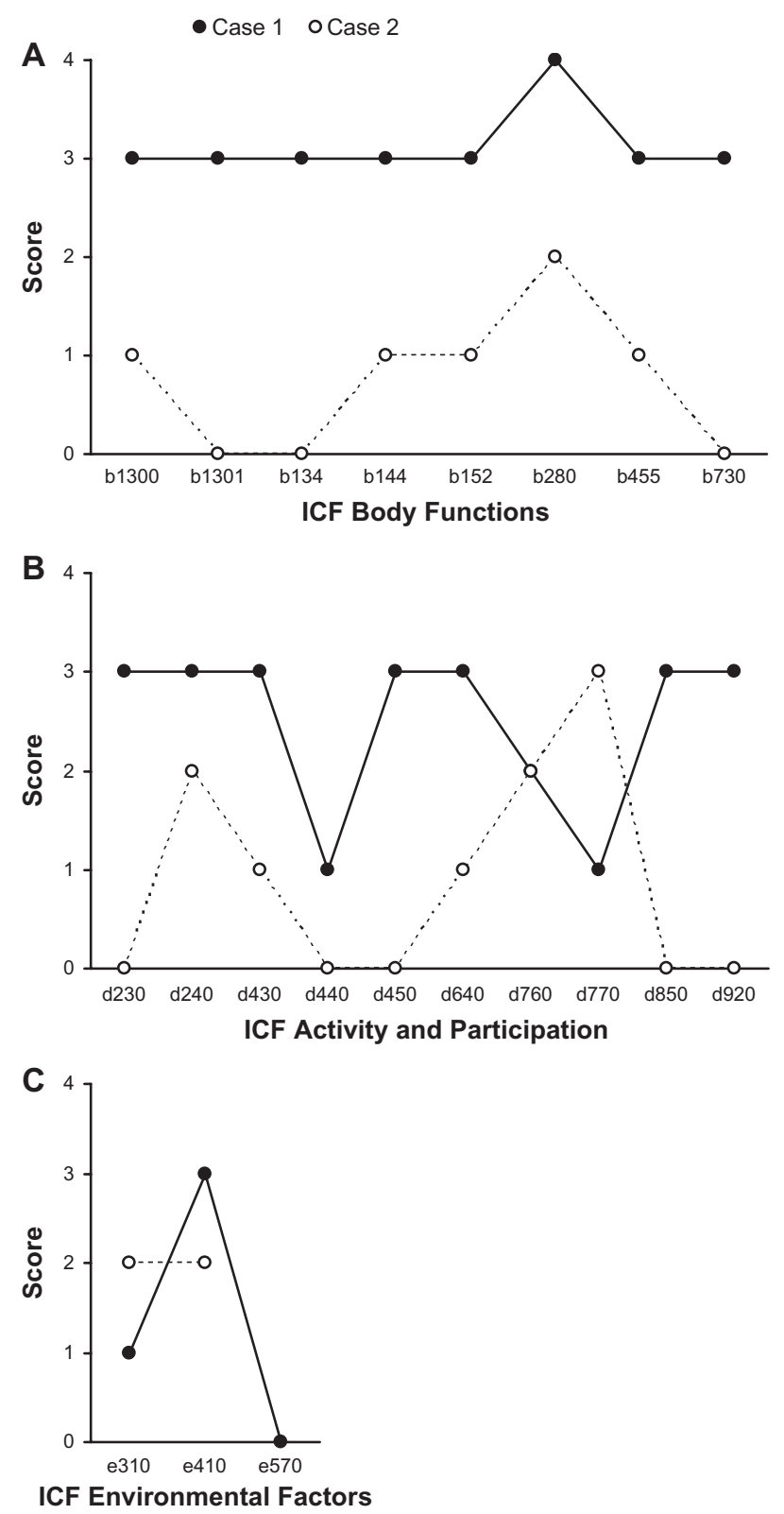

Figure I (A) Body Functions categories: b I300: energy and drive, b 30 I:motivation, b|34: sleep, b|44: memory, b|52: emotional, b280: pain, b455: exercise tolerance, b730: muscle power. (B) Activity and Participation categories: d230: carrying out daily routines, $d 240$ : handling stress, $d 430$ : lifting and carrying, $d 440$ : fine hand use, d450: walking, d640: doing housework, d760: family relationships, d770: intimate relationships, d850: remunerative employment, d920: recreation and leisure. (C) Environment and the categories: e310: support from immediate family, e4I0: individual attitudes from immediate family, e570: social security service and policies. Abbreviation: ICF, International Classification of Functioning, Disability and Health.

points captured the referred patients' variations in functioning status.

\section{Activity and Participation}

Difficulties were found in all important aspects of daily life activities (Figure 2). The "severe" difficulties with highest frequency were: handling stress and other psychological demands (d240) (51\%); in lifting and carrying objects (d430) (51\%), remunerative employment (d850) (58\%), and recreation and leisure (d920) (36\%). The most prominent "moderate" difficulties were: carrying out daily routine (d230) (40\%), handling stress and other psychological demands (d240) (45\%), and doing housework (d640) (45\%) (Figure 2). Few patients had "complete" difficulties.

Fine-motor hand use in these patients, resources were seen in the categories of fine hand use, doing housework, intimate relationships, and family relationships.

\section{Body Functions}

In the component of Body Functions, the severe impairments with the highest frequencies were: sensation of pain (b280) (77\%), exercise tolerance functions (b455) (45\%), sleep functions (b134) (42\%), and emotional functions (b152) $(42 \%)$ ) (Figure 3). The most prominent moderate impairments were in: muscle power functions (b730) (51\%), emotional functions (b152) (49\%), energy level (b1300) (42\%), and in sleep functions (b134) (40\%) (Figure 3). Few patients had complete impairment.

Resources were found in motivation and memory functions.

\section{Environmental Factors}

The most frequent severe barriers were: support from immediate family (e310) (12\%), and attitudes of immediate family (e410) (12\%) (Figure 4). Approximately $25 \%$ of the patients had moderate barriers in support from immediate family (e310), and attitudes of immediate family (e410). Few patients had complete barriers in the component Environmental Factors (Figure 4).

Resources were found in support and attitudes from immediate family. Social security and services, systems, and policies were assessed as a resource in $60 \%$ of the patients.

\section{Discussion}

The modified Brief ICF Core Set for CWP profile was given a workable shape to facilitate the rapid understanding of the initial assessment outcome by any of the rehabilitation team members. At first, the use of the modified Brief ICF Core Set during the team conference was rather time consuming, but after a couple of months of experience, the team assessment took approximately 30 minutes per patient. This can be compared with, due to the lack of CWP studies, a LBP study, where it was found that the clinical feasibility of the ICF Comprehensive Core Set for LBP was affected by the fact that the scoring was rather time consuming. ${ }^{16}$ In that study, the 
- Complete $\square$ Severe $\square$ Moderate $\square$ Mild $\square$ No

Carrying out daily routine $(n=52)$

Handling stress and other psychological demands $(n=53)$

Lifting and carrying objects $(n=53)$

Fine hand use $(n=51)$

Walking $(n=52)$

Doing housework $(n=51)$

Family relationships $(n=52)$

Intimate relationships $(n=39)$

Remunerative employment $(n=53)$

Recreation and leisure $(n=52)$

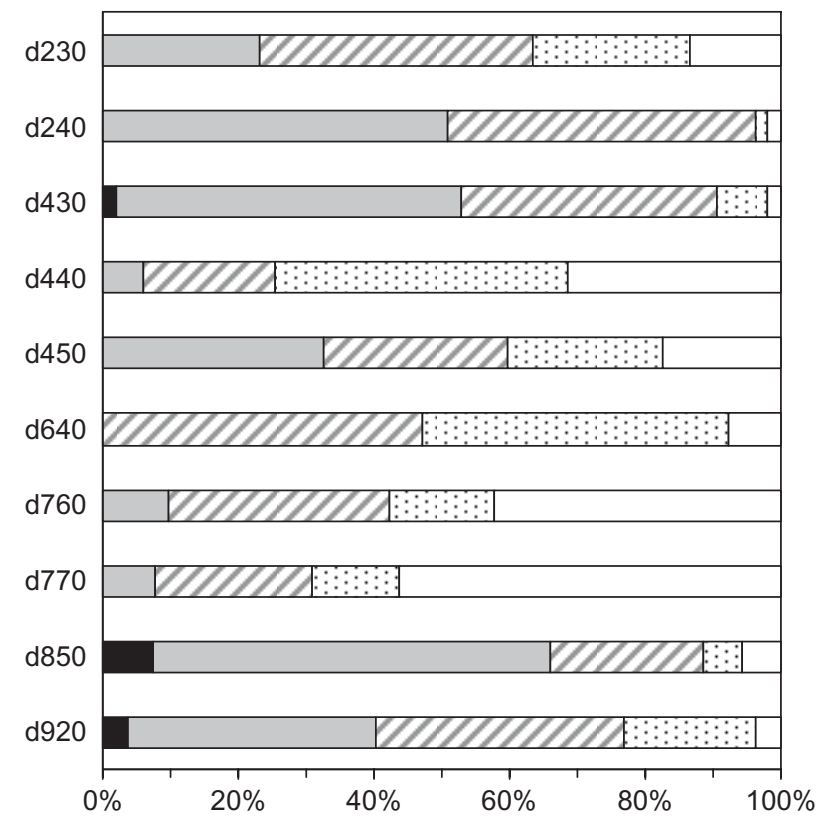

Figure 2 The percentage of patients in each ICF category of Activities and Participation.

Abbreviation: ICF, International Classification of Functioning, Disability and Health.

- Complete $\square$ Severe $\square$ Moderate $\square$ Mild $\square$ No

Energy level $(n=52)$

Motivation $(n=50)$

Sleep functions $(n=53)$

Memory functions $(n=44)$

Emotional functions $(n=53)$

Sensation of pain $(n=53)$

Exercise tolerance functions $(n=51)$

Muscle power functions $(n=52)$

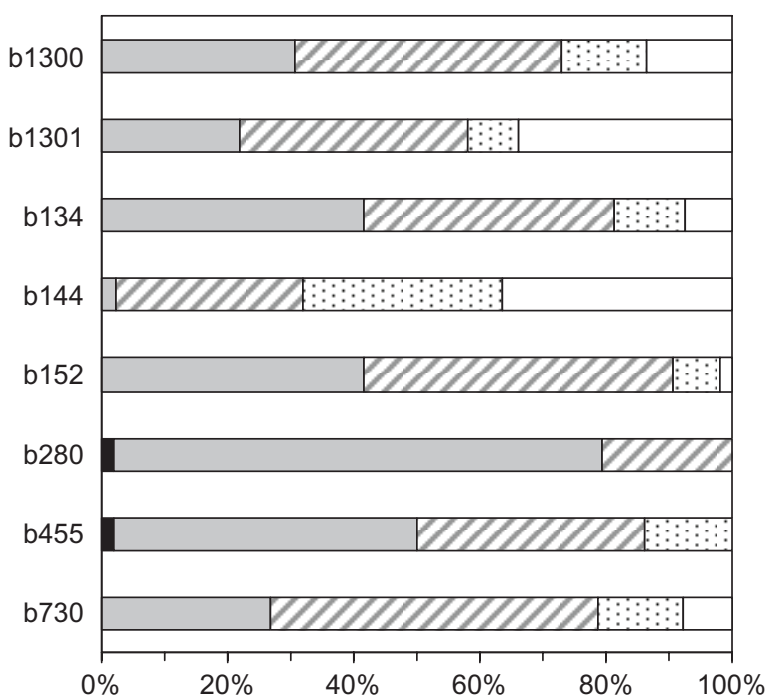

Figure 3 The percentage of patients in each ICF category of Body Functions.

Abbreviation: ICF, International Classification of Functioning, Disability and Health.

Complete $\square$ Severe $\square$ Moderate $\square$ Mild $\square$ No

Support immediate family $(n=50)$

Attitudes of immediate family members $(n=43)$

Social security services, systems and policies $(n=44)$

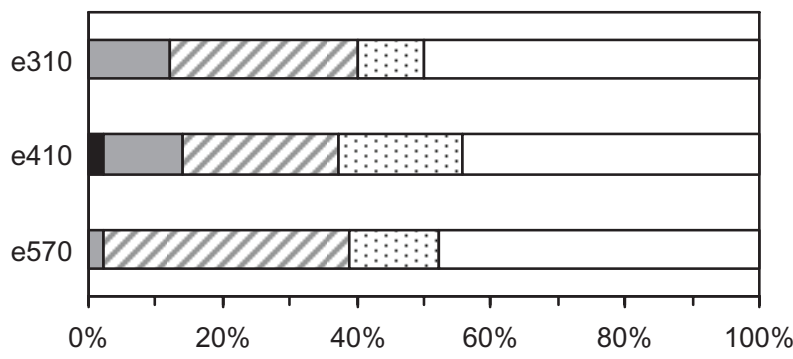

Figure 4 The percentage of patients in each ICF category of Environmental Factors. Abbreviation: ICF, International Classification of Functioning, Disability and Health. 
time spent on coding the ICF Core Set for LBP varied from 10 to 120 minutes (mean 48 minutes, standard deviation [SD] 25 minutes). The coding lasted for $>60$ minutes in $22 \%$ of the cases, while in $5 \%$, the time consumed was $>90$ minutes.

The visual profile provided by the modified Brief ICF Core Set also provided an easily accessible, overall view of the patient's problems and resources, which helped in understanding the functional level of the patient. The profile provided by the modified Brief ICF Core Set for CWP was used as a basis for individual rehabilitation plans and goal setting, thus serving as a link between assessment and interventions, ie, for decisions about content of individual rehabilitation programs.

It should be noted that the study group profiles (Figures 2-4) can be used in two complementary directions; reading first from left to right gives an impression of the severe/moderate impairments, disabilities, and environmental barriers, while reading in the opposite direction, from right to left, gives an idea of the patients' resources, ie, the occurrence of low qualifier numbers can be considered as patient resources. This has particular importance when planning for further vocational rehabilitation. No or mild barriers in the environmental categories also constitute relevant information. Similarly, concerning individual profiles (Figure 1), high numbers in upper parts of the graphs indicate severe/moderate problems, while low numbers in lower parts of the graph suggest resources for that individual.

The two individual profiles (Figure 1) can be used as examples for discussing rehabilitation planning. Case 1 exemplifies how a patient with great difficulties and few resources can be assessed. The difficulties included low motivation for rehabilitation, high impact on activities, and severe pain. This has to be accounted for in the planning of motivational measures, psychological measures, such as cognitive therapy, and a carefully implemented increase in physical and daily activities. The primary long-term goal here would not be resuming work but rather, increasing the patient's ability to manage activities in daily life.

Case 2 (Figure 1) exemplifies a patient with many resources and some difficulties. This patient profile includes high motivation, mild impact on activities (except for intimate relationships), and moderate pain. This patient would need less rehabilitation measures, which might include physical exercises and supportive measures for maintaining working capacity, as a long-term goal.

To our knowledge, no similar study with individual and group profiles (Figures 1-4), including the frequencies of the category qualifiers has been described for CWP. Due to the lack of CWP studies, a study of LBP patients, of similar scope to the present study, was used for comparison; in that study, few impairments/limitations or restrictions were scored as severe and extremely few as complete, while the qualifier zero/no problem showed high frequencies. ${ }^{16}$ In the present study of Swedish CWP patients, a similar pattern of distribution of frequencies was observed, with few or none scored as severe or complete. However, the patients with LBP differed from the CWP patients in the present study in duration of pain and chronicity, since the LBP study also included patients with acute and subacute pain. On account of this, further comparisons between the two studies are not meaningful.

\section{Limitation of the study}

A limitation of the present study is the adaptation made to the original version of the Brief ICF Core Set for CWP, due to the time limitations of the primary assessment. However, the modified profile contained 21 categories, of which 18 were in agreement with the original Brief ICF Core Set for CWP. ${ }^{10}$ Since one of the important aims of the rehabilitation program was work resumption, the category fine hand use (d440) was included. In a focus group study, ${ }^{14} 27$ additional concepts were linked to fine hand use (d440), which may be seen as support for the addition of this category in the present study. ${ }^{14}$

In an extensive study with psychometric analysis, 14 of the categories of the Brief ICF Core Set for CWP were included in the final model. ${ }^{11}$ Those 14 categories did not contain: control of voluntary movement functions (b760), muscle power function (b730), lifting and carrying objects (d430), doing housework (d640), or recreation and leisure (d920), compared with the original list of the 19 categories of the components Body Functions, and Activities and Participation from the Brief ICF Core Set for CWP. ${ }^{10}$ For comparison, in the present study, control of voluntary movement functions (b760) was also excluded. In addition, four categories were excluded due to apprehension of difficulties in their assessment, analysis, and scoring within a limited time; these were: psychomotor functions (b147), content of thought (b1602), solving problems (d175) and support from health professionals (e355). Excluding categories may limit an assessment; however, we argue that the modified Core Set profile covered the essential parts of the patients' functioning. There are, in fact, several ongoing scientific studies investigating the development of the Brief and Comprehensive ICF Core Sets for CWP. ${ }^{11,14,33,34}$

Another limitation may have been the mix of primary diagnoses in the patients included. However, in our opinion, the number of pain locations documented for each patient 
has probably been a sufficient indicator of the spreading of pain (see Table 3 ).

\section{Clinical experience and implications}

By using the modified Brief ICF Core Set for CWP, the team members experienced value in discussing the resulting profile, and the team-based assessment became more structured. By visualizing the completed easy-to-read profile, the team members got an overview of the patients' abilities and disabilities. This can serve as a tool when discussing the rehabilitation plan with the patient. The profile provided by the modified Brief ICF Core Set for CWP may facilitate the dialogue between team members during consensus discussions and thus, probably, improve team cooperation.

\section{Disclosure}

The authors report no conflicts of interest in this work.

\section{References}

1. Hoefsmit N, Houkes I, Nijhuis FJ. Intervention characteristics that facilitate return to work after sickness absence: a systematic literature review. J Occup Rehabil. 2012;22(4):462-477.

2. Norlund A, Ropponen A, Alexanderson K. Multidisciplinary interventions: review of studies of return to work after rehabilitation for low back pain. J Rehabil Med. 2009;41(3):115-121.

3. Scascighini L. Toma V, Dober-Spielmann S, Sprott H. Multidisciplinary treatment for chronic pain: a systematic review of interventions and outcomes. Rheumatology (Oxford). 2008;47(5):670-678.

4. Pietilä Holmner E. Fahlström M, Nordström A. The effects of interdisciplinary team assessment and a rehabilitation program for patients with chronic pain. Am J Phys Med Rehabil. 2013;92(1):77-83.

5. Manley S. The rehabilitation team. In: Grabois M, Garrison S, Hart K, Lehmkuhl L, editors. Physical Medicine and Rehabilitation. Malden, Blackwell Science; 2000:26-32.

6. Chamberlain MA, Fialka Moser V, Schüldt Ekholm K, O’Connor RJ, Herceg M, Ekholm J. Vocational rehabilitation: an educational review. J Rehabil Med. 2009;41(11):856-869.

7. World Health Organization (WHO). International Classification of Functioning Disability and Health. Geneva: World Health Organization; 2001.

8. Wormgoor ME, Indahl A, van Tulder MW, Kemper HC. Functioning description according to the icf model in chronic back pain: disablement appears even more complex with decreasing symptom-specificity. $J$ Rehabil Med. 2006;38(2):93-99.

9. Cieza A, Stucki G, Weigl M, et al. ICF Core Sets for low back pain. J Rehabil Med. 2004;44(Suppl 44):S69-S74.

10. Cieza, A. Stucki G, Weigl M, et al. ICF Core Sets for chronic widespread pain. J Rehabil Med. 2004;(Suppl 44):S63-S68.

11. Prodinger B, Salzberger T, Stucki G, Stamm T, Cieza A. Measuring functioning in people with fibromyalgia (FM) based on the international classification of functioning, disability and health (ICF) - a psychometric analysis. Pain Pract. 2012;12(4):255-265.

12. Cerniauskaite M, Quintas R, Boldt C, et al. Systematic literature review on ICF from 2001 to 2009: its use, implementation and operationalisation. Disabil Rehabil. 2011;33(4):281-309.

13. Mullis R, Barber J, Lewis M, Hay E. ICF core sets for low back pain: do they include what matters to patients? J Rehabil Med. 2007;39(5):353-357.
14. Hieblinger R, Coenen M, Stucki G, Winkelmann A, Cieza A. Validation of the International Classification of Functioning, Disability and Health Core Set for chronic widespread pain from the perspective of fibromyalgia patients. Arthritis Res Ther. 2009;11(3):R67.

15. Hilfiker R, Obrist S, Christen G, Lorenz T, Cieza A. The use of the comprehensive International Classification of Functioning, Disability and Health Core Set for low back pain in clinical practice: a reliability study. Physiother Res Int. 2009;14(3):147-166.

16. Bautz-Holter E, Sveen U, Cieza A, Geyh S, Røe C. Does the International Classification of Functioning, Disability and Health (ICF) core set for low back pain cover the patients' problems? A cross-sectional contentvalidity study with a Norwegian population. Eur J Phys Rehabil Med. 2008;44(4):387-397.

17. Røe C, Sveen U, Cieza A, Geyh S, Bautz-Holter E. Validation of the Brief ICF core set for low back pain from the Norwegian perspective. Eur J Phys Rehabil Med. 2009;45(3):403-414.

18. Maini M, Nocentini U, Prevedini A, Giardini A, Muscolo E. An Italian experience in the ICF implementation in rehabilitation: preliminary theoretical and practical considerations. Disabil Rehabil, 2008;30(15): $1146-1152$.

19. Nyberg V, Sanne H, Sjölund BH. Swedish quality registry for pain rehabilitation: purpose, design, implementation and characteristics of referred patients. J Rehabil Med. 2011;43(1):50-57.

20. Nyberg V. Pain Rehabilitation in Sweden: A Quality Registry Study [doctoral thesis]. Umeå: Umeå University; 2011. Available from: http:// umu.diva-portal.org/smash/record.jsf?searchId=1\&pid=diva2:416699. Accessed June 3, 2013.

21. Gard G, Larsson A. Focus on motivation in the work rehabilitation planning process: a qualitative study from the employer's perspective. J Occup Rehabil. 2003;13(3):159-167.

22. Taft C, Karlsson J, Sullivan M. Performance of the Swedish SF-36 version 2.0. Qual Life Res. 2004;13(1):251-256.

23. Lisspers J, Nygren A, Söderman E. Hospital Anxiety and Depression Scale (HAD): some psychometric data for a Swedish sample. Acta Psychiatr Scand. 1997;96(4):281-286.

24. Zigmond AS, Snaith RP. The hospital anxiety and depression scale. Acta Psychiatr Scand. 1983;67(6):361-370.

25. Burström K, Johannesson M, Diderichsen F. Swedish population health-related quality of life results using the EQ-5D. Qual Life Res. 2001;10(7):621-635.

26. Bergström G, Jensen IB, Bodin L, Linton SJ, Nygren AL, Carlsson SG. Reliability and factor structure of the Multidimensional Pain Inventory Swedish Language version (MPI-S). Pain. 1998;75(1):101-110.

27. McCracken LM, Volwes KE, Eccleston C. Acceptance of chronic pain: component analysis and a revised assessment method. Pain. 2004;107(1-2):159-166.

28. Missaghi-Wedefalk M. Test Instrument for profile of physical ability = Tippa. Nordisk Fysioterapi. 2004;8:74-83.

29. Fisher AG. The assessment of IADL motor skills: an application of manyfaceted Rasch analysis. Am J Occup Ther. 1993;47(4):319-329.

30. Dusik LA, Menard MR, Cooke C, Fairburn SM, Beach GN. Concurrent validity of the ERGOS work simulator versus conventional functional capacity evaluation techniques in a workers' compensation population. J Occup Med. 1993;35(8):759-767.

31. Lundberg M, Styf J, Carlsson S. A Psychometric evaluation of the Tampa Scale for Kinesiophobia - from a physiotherapeutic perspective. Physiotherapy Theory and Practice. 2004;20(2):121-133.

32. Larsson B, Björk J, Börsbo B, Gerdle B. A systematic review of risk factors associated with transitioning from regional musculoskeletal pain to chronic widespread pain. Eur J Pain. 2012;16(8):1084-1093.

33. Brage S, Donceel P, Falez F; Working Group of the European Union of Medicine in Assurance and Social Security. Development of ICF core set for disability evaluation in social security. Disabil Rehabil. 2008;30(18):1392-1396.

34. Finger ME, Escorpizo R, Glässel A, et al. ICF Core Set for vocational rehabilitation: results of an international consensus conference. Disabil Rehabil. 2012;34(5):429-438. 
Journal of Multidisciplinary Healthcare

Dovepress

\section{Publish your work in this journal}

The Journal of Multidisciplinary Healthcare is an international, peerreviewed open-access journal that aims to represent and publish research in healthcare areas delivered by practitioners of different disciplines. This includes studies and reviews conducted by multidisciplinary teams as well as research which evaluates the results or conduct of such teams or healthcare processes in general. The journal covers a wide range of areas and welcomes submission from practitioners at all levels, from all over the world. The manuscript management system is completely online and includes a very quick and fair peer-review system. Visit http://www.dovepress.com/testimonials.php to read real quotes from published authors.

Submit your manuscript here: http://www.dovepress.com/journal-of-multidisciplinary-healthcare-journal 